\title{
Influência das frações granulométricas de agregados miúdos reciclados no comportamento de argamassas de cimento
}

\author{
Influence of the granulometric fractions of recycled sands \\ on the mechanical properties of Portland cement mortars
}

\section{Cássia Rabelo Correa \\ Cláudio Henrique Pereira João Henrique Silva Rêgo}

\section{Resumo}

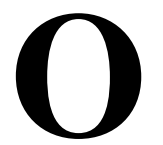

trabalho parte do pressuposto de que as frações granulométricas dos agregados miúdos reciclados apresentam características diferentes, as quais influenciariam de forma distinta no comportamento mecânico das argamassas. Nesse sentido, o artigo propõe o estudo das frações granulométricas de duas areias recicladas: areia de resíduo de construção e demolição (AR1) e areia de resíduo de concreto (AR2). As areias recicladas foram submetidas a ensaios de caracterização física e FRX, e na sequência foram incorporadas em argamassas. Os resultados revelaram que as areias recicladas são formadas por dois grupos com características e tendências distintas: (1) o grupo das "frações grossas", formado pelas frações grossa e média-grossa; e (2) o grupo das "frações finas", formado pelas frações média-fina e fina. O estudo mostrou que a diversidade dos materiais de origem da AR1 fez com que a pasta de cimento se diluísse em suas frações; ao contrário, com a AR2, a pasta se concentrou, principalmente nas "frações finas". Sendo assim, as "frações finas" da AR1 se mostraram semelhantes à areia do IPT (utilizada como referência) e mais adequadas do que as "frações finas" da AR2. O estudo concluiu que existem diferenças nos comportamentos mecânicos das argamassas conforme a fração granulométrica é substituída, o que amplia as possibilidades de aplicação de agregados miúdos reciclados em designs de misturas cimentícias.

Palavras-chave: Agregados miúdos reciclados. Resíduo de construção e demolição. Resíduo de concreto. Frações granulométricas. Comportamento mecânico.

${ }^{1}$ Cássia Rabelo Correa ${ }^{1}$ Instituto Federal de Brasília Brasília - DF - Brasil

\section{${ }^{2}$ Cláudio Henrique Pereira} ${ }^{2}$ Universidade de Brasília Brasília - DF - Brasil

${ }^{3}$ João Henrique Silva Rêgo ${ }^{3}$ Universidade de Brasília Brasília - DF - Brasil

Recebido em 01/08/18 Aceito em 01/04/20

\section{Abstract}

This research study is based on the assumption that the granulometric fractions of recycled small aggregates present different characteristics and, therefore, these characteristics would influence the mechanical behaviour of mortars differently. Thispaper proposes the study of the granulometric fractions of two recycled sands: SD1 (sand from construction waste and demolition) and SD2 (sand from concrete waste). The recycled sands were submitted to physical characterisation and FRX tests, and subsequently incorporated in mortars. The results showed that the recycled sands form two groups with different characteristics and tendencies: (1) the "coarse fractions" group, formed by the coarse fractions and (2) "fine fractions" group, formed by the fine and fine-medium fractions. The study demonstrated that the diversity of the source materials of the SD1 sand led the cement paste to dilute in its fractions, whereas in theSD2 sand, it concentrated mainly in the "fine fractions". Thus, the "fine fractions" of the SD1 sand are similar to the IPT sand (used as reference) and more adequate than those of the SD2 sand. The study concluded that the mechanical behaviour of mortars differ as the granulometric fraction is replaced, increasing the possibilities of application of recycled small aggregates in the design of cement mixtures.

Keywords: Recycled small aggregates. Construction waste and demolition. Concrete waste. Granulometric fractions. Mechanical behaviour. v. 20, n. 4, p. 305-317, out./dez. 2020. 


\section{Introdução}

A questão ambiental é uma preocupação global, e reduzir os impactos causados pelas atividades humanas que interferem no meio ambiente faz parte das exigências atuais para alcançar o desenvolvimento sustentável. O setor da construção civil consome grande quantidade de recursos naturais, além de gerar um volume elevado de resíduos. No Brasil, de acordo com a Associação Brasileira para Reciclagem de Resíduos da Construção Civil e Demolição, os resíduos gerados pelas atividades ligadas à construção civil representam, em média, $40 \%$ a $70 \%$ da quantidade total dos resíduos gerados anualmente, enquanto na União Europeia esses resíduos representam cerca de 25\% a 30\% (ASSOCIAÇÃO..., 2015). Observa-se hoje tendência atual para minimizar as consequências danosas causadas por essas ações com o emprego de resíduos na própria construção civil. Como forma de reduzir o volume descartado de resíduos, o uso de agregado reciclado na produção de concretos e argamassas tem se mostrado uma opção sustentável.

Neste contexto, os agregados miúdos reciclados têm alcançado grande interesse internacional devido, principalmente, a questões socioambientais (PACHECO-TORGAL, 2013). Gerados muitas vezes de forma involuntária durante o processo de britagem, eles representam, em massa, aproximadamente $50 \%$ do material beneficiado (ANGULO, 2005). Logo, estudos sobre areias recicladas se justificam, pois o tema assume importância não só nas áreas social e ambiental como também no segmento econômico, uma vez que a demanda por esse material poderá viabilizar a implantação e o funcionamento de usinas de reciclagem, e na área técnica e científica, com o surgimento de novos materiais e componentes de menor impacto para uso na construção civil.

Os resíduos de construção e demolição (RCD) podem conter não só resíduos das construções e demolições, como também resíduos de concreto, gerados, por exemplo, por fábricas de pré-moldados ou concreteiras, fazendo com que os RCD no Brasil sejam compostos de cerca de $70 \%$ de concreto e/ou argamassa (ANGULO, 2005; ULSEN, 2011). Em relação aos resíduos de concreto (RC), estes são gerados por cimenteiras, concreteiras e fábricas de pré-moldados, e são compostos basicamente de concreto e argamassa (PACHECO-TORGAL, 2013).

Os RCD e RC são heterogêneos, o que, segundo Malta et al. (2014), dificulta o desenvolvimento de métodos e modelos capazes de controlar e predizer as características dos agregados reciclados, tornando complexa a determinação de sua influência sobre as propriedades físicas, químicas e mecânicas dos materiais cimentícios.

Quando os resíduos contendo concretos e argamassas são britados, parte da pasta de cimento original permanece aderida às partículas do mineral, fazendo com que o agregado reciclado apresente uma superfície rugosa e se torne mais poroso e menos denso. Logo, a pasta de cimento seria responsável pela maior capacidade de absorção de água e pelos menores valores de massa específica aparente e massa unitária dos agregados reciclados (ULSEN et al., 2010, 2013; PACHECO-TORGAL, 2013; KAHN et al., 2014; MIRANDA, 2014; SILVA; DE BRITO; DHIR, 2014). Os valores de massa unitária dos agregados reciclados se devem, além da densidade e da porosidade do conjunto que forma o material de origem, ao formato irregular de suas partículas, que podem interferir no empacotamento dos grãos (MEHTA; MONTEIRO, 2014). A absorção de água, a massa unitária (empacotamento) e a massa específica aparente vão variar com a granulometria do agregado reciclado, dependendo também da maior ou menor presença de pasta de cimento (CABRAL, 2007), sendo que a proporção de material mais denso aumenta nas frações mais finas dos agregados reciclados (ULSEN et al., 2014).

Apesar da presença da pasta de cimento nesse agregado, algumas pesquisas (EVANGELISTA; DE BRITO, 2010; MARTÍNEZ et al.,2013; MALTA et al., 2014; RODRIGUES; FUCALE, 2014; BALDUSCO DA SILVA et al., 2015; BEDOYA; DZUL, 2015; EVANGELISTA et al., 2015) têm mostrado que as areias recicladas, tanto de $\mathrm{RCD}$, quanto de $\mathrm{RC}$, podem apresentar características técnicas aceitáveis e comportamentos mecânicos compatíveis aos das areias naturais. Contudo, tais estudos normalmente tentam enquadrar as areias recicladas à curva granulométrica das areias convencionais, algo complexo e ainda objeto de discussão no meio técnico (MEHTA; MONTEIRO, 2014).

Esta pesquisa foi idealizada com o intuito de contribuir no entendimento e determinação das características e propriedades de agregados miúdos reciclados destinados à produção de concretos e argamassas. Propõe-se a apresentação de uma metodologia experimental para identificar e caracterizar possíveis diferenças físicas e químicas do agregado miúdo reciclado, com a separação granulométrica em quatro intervalos granulométricos e análise sistêmica de cada uma delas. O objetivo é avaliar duas areias recicladas de diferentes origens e composições (RCD e RC) e analisar se suas frações granulométricas apresentam 
heterogeneidade perceptível, com características distintas que possam influenciar nas propriedades no estado fresco e no comportamento mecânico de argamassas de cimento.

\section{Materiais e métodos}

\section{Materiais}

A areia reciclada 1 (AR1) é um agregado miúdo proveniente de uma usina de reciclagem que recebe RCD de diversas obras do Distrito Federal. Na usina, os resíduos passam primeiramente por uma triagem manual, da qual apenas resíduos de cor cinza seguem para as próximas etapas de beneficiamento. Na sequência, o material passa por dois britadores de mandíbula e um moinho de martelos (via úmida). Por fim, o agregado segue para as peneiras, onde acontecem simultaneamente a lavagem e a classificação.

A areia reciclada 2 (AR2), que foi beneficiada em laboratório,é um agregado miúdo proveniente da britagem de corpos de prova de diferentes traços de concretos, com idades superiores a 28 dias. Os corpos de prova são originários de uma usina de concreto, da cidade de Brasília, DF, que utiliza agregados de origem calcária e ígnea. Os corpos de prova passaram por dupla britagem em um britador de mandíbula de escala laboratorial e, posteriormente, por uma lavagem em água corrente.

A areia natural (AN), utilizada como agregado de referência na pesquisa, é a areia normal brasileira. A produção, em quatro frações granulométricas distintas, e o fornecimento desse material são atribuições do Instituto de Pesquisas Tecnológicas (IPT), conforme estabelecido na NBR 7214 - Areia normal para ensaio de cimento (ABNT, 2015).

$\mathrm{O}$ aditivo superplastificante escolhido é à base de policarboxilato, com teor de sólido de $40 \%$ e massa específica de $1,040 \mathrm{~g} / \mathrm{cm}^{3}$. Foi utilizado na produção das argamassas recicladas por apresentar compatibilidade com o aglomerante, com o intuito de manter a mesma consistência da argamassa de referência.

O aglomerante utilizado foi o cimento Portland CPII-F-32, de um único lote e fornecido para o mercado consumidor em embalagens de $50 \mathrm{~kg}$, em conformidade com a NBR 7215 (ABNT, 2019).

Cada uma das areias recicladas (AR1 e AR2) foi separada, por peneiramento, em quatro frações granulométricas, similares às da areia normal brasileira. A Tabela 1 descreve as frações granulométricas das areias utilizadas na pesquisa.

\section{Métodos}

O estudo foi dividido em duas partes:

(a) parte 1: avaliação das frações granulométricas das areias recicladas no estado anidro; e

(b) parte 2: avaliação das argamassas com areias recicladas no estado fresco e endurecido.

\section{Parte 1: avaliação das frações granulométricas das areias recicladas no estado anidro}

Através dos ensaios de caracterização física e da análise química foi possível caracterizar, de forma sistêmica, cada uma das quatro frações granulométricas das areias AR1 e AR2 e as areias na condição areia composta (composição em partes iguais das quatro frações). Para fins de comparação, as frações granulométricas da areia de referência foram também submetidas à caracterização físico-química.

Tabela 1 - Descrição das frações granulométricas das areias estudadas

\begin{tabular}{l|l}
\hline \multicolumn{1}{c|}{ Frações } & \multicolumn{1}{c}{ Descrição das frações - intervalos } \\
\hline Grossa & areia passante na peneira de malha $2,40 \mathrm{~mm}$ e retida na de $1,18 \mathrm{~mm}$ \\
Média-grossa & areia passante na peneira de malha $1,18 \mathrm{~mm}$ e retida na de $0,60 \mathrm{~mm}$ \\
Média-fina & areia passante na peneira de malha $0,60 \mathrm{~mm}$ e retida na de $0,30 \mathrm{~mm}$ \\
Fina & areia passante na peneira de malha $0,30 \mathrm{~mm}$ e retida na de $0,15 \mathrm{~mm}$ \\
\hline
\end{tabular}


Foram realizados os seguintes ensaios:

(a) determinação de massa unitária segundo a NBR NM 45 (ABNT, 2004a);

(b) determinação da absorção de água segundo a NBRNM30 (ABNT, 2001); e

(c) determinação da massa específica segundo a NBR NM 52 (ABNT, 2003).

O fator de empacotamento foi calculado através das Equações 1 e 2, apresentadas a seguir, conforme sugerem Girardi, Martins Filho e Carasek (2017).

$\mathrm{E} 0=100-[\mathrm{e} /(1+\mathrm{e}) \times 100]$

Sendo:

$\mathrm{E} 0=\mathrm{ME} / \mathrm{MU}-1$

Onde:

e: índice de vazios [adimensional];

ME: massa específica $\left[\mathrm{g} / \mathrm{cm}^{3}\right]$;

MU: massa unitária $\left[\mathrm{g} / \mathrm{cm}^{3}\right]$; e

E0: fator de empacotamento [adimensional].

Com o objetivo de identificar os constituintes químicos presentes nas areias recicladas, análises químicas de fluorescência de raios X (FRX) foram realizadas em espectrômetro de fluorescência de raios X por energia dispersiva, modelo EDX-720HS, da marca Shimadzu.

\section{Parte2: avaliação das argamassas com areias recicladas no estado fresco e endurecido}

A confecção das argamassas seguiu padrão análogo ao recomendado para as argamassas utilizadas nas avaliações de cimento, conforme a NBR 7215 (ABNT, 2019). O traço proposto pela NBR 7215 (ABNT, 2019) compreende $640 \mathrm{~g}$ de cimento, $300 \mathrm{~g}$ de água e $468 \mathrm{~g}$ de cada uma das frações granulométricas das areias (grossa, média-grossa, média-fina e fina), totalizando $1.872 \mathrm{~g}$ de areia.

Para a avaliação da interferência das areias recicladas no estado fresco e endurecido foram produzidas argamassas com substituições de $25 \%$ das frações da AN, como o objetivo de testar separadamente cada uma das frações granulométricas das areias recicladas. Sendo assim, uma substituição de $25 \%$ significa que uma das frações granulométricas da $\mathrm{AN}(468 \mathrm{~g})$ foi substituída pela fração correspondente de areia reciclada (dados os devidos ajustes de massa). Também foram confeccionadas argamassas com 100\% de areia reciclada (condição areia composta) e argamassa de referência com 100\% de areia do IPT.

As porcentagens de substituição de cada uma das frações granulométricas, assim como a descrição das nomenclaturas adotadas para as argamassas, estão apresentadas na Tabela 2, a seguir.

Para garantir não só a trabalhabilidade, mas também o volume da mistura a ser produzida, além das massas de água, as massas de agregado reciclado foram ajustadas (TAYLOR, 1997; LEITE, 2001; MALTA et al., 2014). Mantendo o mesmo volume da argamassa de referência, foi realizada a substituição do agregado natural pelo reciclado em volume, e feitos os devidos ajustes nas massas secas das argamassas recicladas, segundo a NBR 15116 (ABNT, 2004b). Com o intuito de manter constante a relação água-cimento (a/c) das misturas, foram realizados ajustes nas massas de água apenas para a compensação da absorção de água do agregado reciclado, conforme Leite (2001). Para além dos ajustes das massas de água,fez-se necessário o uso de aditivo superplastificante, que foi ajustado nas argamassas recicladas para alcançar a consistência da argamassa de referência com trabalhabilidade fixada pelo espalhamento na mesa de consistência, em $125 \pm 10$ $\mathrm{mm}$.

Para o processo de mistura, as areias foram utilizadas na condição seca ao forno $\left(105 \pm 5^{\circ} \mathrm{C}\right)$, juntamente com o cimento CPII-F-32, a água e o aditivo superplastificante.

Os procedimentos de moldagem, adensamento e cura dos corpos de prova seguiram as recomendações da NBR 7215 (ABNT, 2019). 
Tabela 2 - Nomenclaturas e percentuais de substituição adotados para as argamassas

\begin{tabular}{|c|c|c|}
\hline Descrição & Nomenclatura & Substituição (\%) \\
\hline Argamassa composta pelas quatro frações granulométricas da AN & $\mathrm{ARG}_{\mathrm{AN}}$ & - \\
\hline $\begin{array}{l}\text { Argamassa com substituição da fração grossa da AN pela fração } \\
\text { grossa da AR1 }\end{array}$ & $\mathrm{ARG}_{\mathrm{AR} 1 \mathrm{G}}$ & 25 \\
\hline $\begin{array}{l}\text { Argamassa com substituição da fração média-grossa da AN pela } \\
\text { fração média-grossa da AR1 }\end{array}$ & $\mathrm{ARG}_{\mathrm{AR} 1 \mathrm{MG}}$ & 25 \\
\hline $\begin{array}{l}\text { Argamassa com substituição da fração média-fina da AN pela } \\
\text { fração média-fina da AR1 }\end{array}$ & $\mathrm{ARG}_{\mathrm{AR} 1 \mathrm{MF}}$ & 25 \\
\hline $\begin{array}{l}\text { Argamassa com substituição da fração fina da AN pela fração fina } \\
\text { da AR1 }\end{array}$ & $\mathrm{ARG}_{\mathrm{AR} 1 \mathrm{~F}}$ & 25 \\
\hline $\begin{array}{l}\text { Argamassa com substituição das quatro frações da AN pelas quatro } \\
\text { frações da AR1 (AR1 composta) }\end{array}$ & $\mathrm{ARG}_{\mathrm{AR} 1100 \%}$ & 100 \\
\hline $\begin{array}{l}\text { Argamassa com substituição da fração grossa da AN pela fração } \\
\text { grossa da AR2 }\end{array}$ & $\mathrm{ARG}_{\mathrm{AR} 2 \mathrm{G}}$ & 25 \\
\hline $\begin{array}{l}\text { Argamassa com substituição da fração média-grossa da AN pela } \\
\text { fração média-grossa da AR2 }\end{array}$ & $\mathrm{ARG}_{\mathrm{AR} 2 \mathrm{MG}}$ & 25 \\
\hline $\begin{array}{l}\text { Argamassa com substituição da fração média-fina da AN pela } \\
\text { fração média-fina da AR2 }\end{array}$ & $\mathrm{ARG}_{\mathrm{AR} 2 \mathrm{MF}}$ & 25 \\
\hline $\begin{array}{l}\text { Argamassa com substituição da fração fina da AN pela fração fina } \\
\text { da AR2 }\end{array}$ & $\mathrm{ARG}_{\mathrm{AR} 2 \mathrm{~F}}$ & 25 \\
\hline $\begin{array}{l}\text { Argamassa com substituição das quatro frações da AN pelas quatro } \\
\text { frações da AR2 (AR2 composta) }\end{array}$ & $\mathrm{ARG}_{\mathrm{AR} 2100 \%}$ & 100 \\
\hline
\end{tabular}

Os ensaios de resistência à compressão axial seguiram as recomendações da NBR 7215 (ABNT, 2019), e os ensaios de resistência à tração por compressão diametral, as recomendações da NBR 7222 (ABNT, 2011), ambos realizados na idade de 28 dias.

Contando com o auxílio da ferramenta computacional Statistical Package for the Social Sciences (SPSS), versão 23.0, foram aplicados os testes estatísticos de duas variáveis: Teste $t$ entre amostras independentes e Teste de Levene. Assim foi possível testar a homogeneidade da variância e a igualdade de médias das características físicas das areias e das propriedades mecânicas das argamassas.

\section{Resultados e discussão}

\section{Resultados da avaliação das frações granulométricas das areias recicladas no estado anidro}

\section{Ensaios de caracterização física}

A seguir são apresentadas as taxas de fator de empacotamento dos grãos (E0) das três areias na condição areia composta (Tabela 3).

Na sequência são apresentados os resultados dos ensaios de caracterização física da areia de referência AN e das areias recicladas AR1 e AR2 nas condições estudadas (Figuras 1 e 2).

Os resultados obtidos nos ensaios foram submetidos a estudos estatísticos que mostram que a maior parte das médias dos valores de massa unitária, absorção de água e massa específica das frações grossa e médiagrossa das areias recicladas pertence a uma mesma população, pois não apresentam significância estatística. Similarmente, as médias das frações média-fina e fina pertencem a outra população, pois também não apresentam significância estatística entre si (Tabela 4).

Após essas constatações, optou-se pela separação das areias AR1 e AR2 em dois grupos de frações: um denominado de "frações grossas", composto pelas frações grossa e média-grossa; e outro denominado de "frações finas", composto pelas frações média-fina e fina. Para a condição areia composta, constatou-se que a maior parte das médias dos valores apresenta significância estatística em relação às "frações grossas" e às "frações finas" (Tabela 4). 
Tabela 3 - Fator de empacotamento dos grãos na condição areia composta

\begin{tabular}{c|c}
\hline Condição areia composta & E0 (\%) \\
\hline AN & 68,2 \\
AR1 & 73,7 \\
AR2 & 65,4 \\
\hline
\end{tabular}

Figura 1 - Gráfico com as frações das areias AN, AR1 e AR2: massa unitária $\left(\mathrm{kg} / \mathrm{m}^{3}\right)$

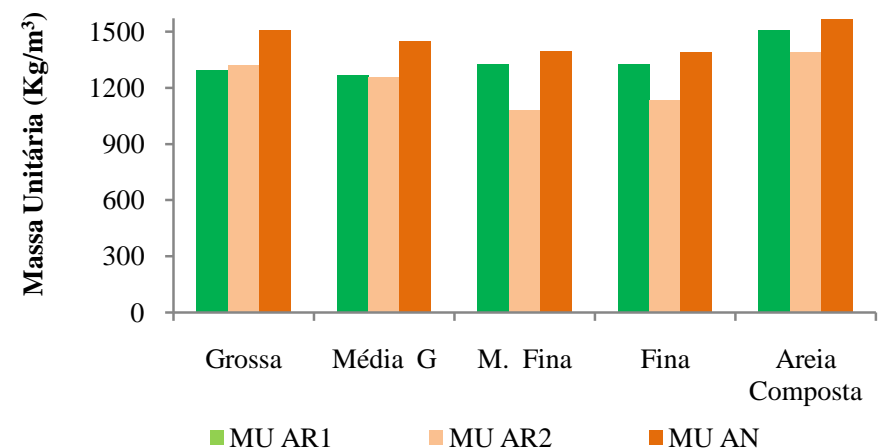

Figura 2 - Gráficos com as frações das areias AN, AR1 e AR2

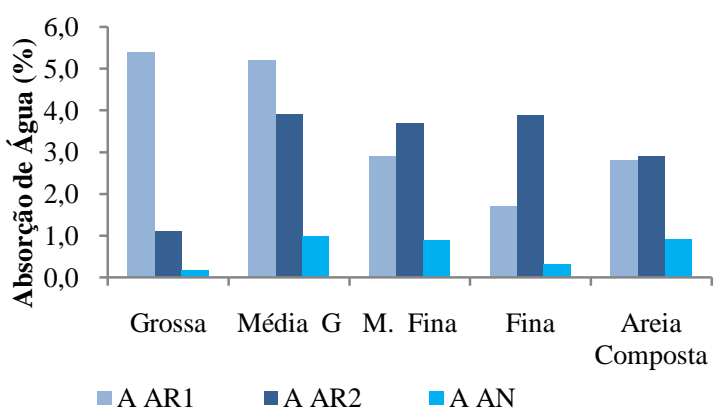

(a) Absorção de água (\%)

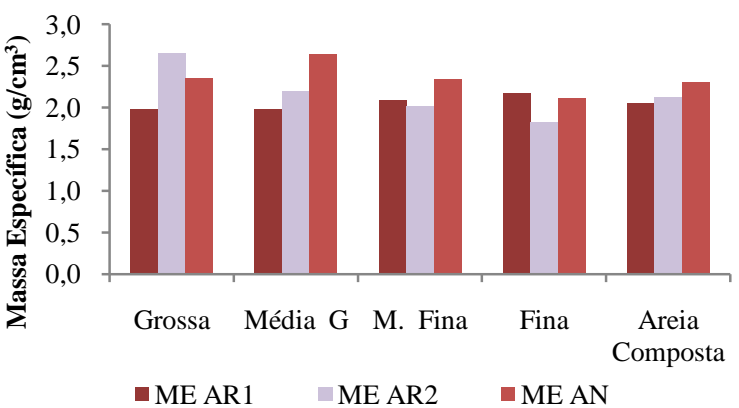

(b) Massa específica aparente $\left(\mathrm{g} / \mathrm{cm}^{3}\right)$

Tabela 4 - Resultados para o Teste $\mathrm{t}$ de amostras independentes e Teste de Levene para as condições estudadas das areias recicladas

\begin{tabular}{l|c|c|c|c}
\hline Condições estudadas & $\begin{array}{c}\text { Fração } \\
\text { grossa }\end{array}$ & $\begin{array}{c}\text { Fração média- } \\
\text { grossa }\end{array}$ & $\begin{array}{c}\text { Fração } \\
\text { média-fina }\end{array}$ & $\begin{array}{c}\text { Fração } \\
\text { fina }\end{array}$ \\
\hline Fração grossa & $=$ & $=$ & $\neq$ & $\neq$ \\
Fração média-grossa & $=$ & $=$ & $\neq$ & $\neq$ \\
Fração média-fina & $\neq$ & $\neq$ & $=$ & $=$ \\
Fração fina & $\neq$ & $\neq$ & $=$ & $=$ \\
Areia composta & $\neq$ & $\neq$ & $\neq$ & $\neq$ \\
\hline
\end{tabular}

Notas: (=) Não há significância estatística; e $(\neq)$ Há significância estatística.

As areias recicladas apresentam massas unitárias menores e valores de absorção de água maiores do que a areia de referência (Figuras 1 e 2a). Os valores de massa específica (Figura 2b) não apresentam diferença estatística significativa entre as areias recicladas e a areia de referência, com exceção para as "frações grossas" da AR1, que apresentam massa específica menor que a da AN.

Em agregados reciclados, menores valores de massa unitária significam presença de pasta de cimento, a qual, eleva os valores de absorção de água dos agregados (PACHECO-TORGAL, 2013; MALTA et al., 2014; MEHTA; MONTEIRO, 2014). Como as areias recicladas são provenientes da britagem de resíduos de 
construção e demolição, e de concreto, era esperada a presença de pasta de cimento nas areias AR1 e AR2. Logo, é compreensível que elas apresentem menores valores de massa unitária e maiores valores de absorção de água que a AN.

No que se refere à massa unitária e ao fator de empacotamento na condição areia composta, observa-se que, apesar de a AR1 apresentar fator de empacotamento 7\% maior do que a AN, aquela apresenta massa unitária cerca de $4 \%$ menor do que a areia de referência (Tabela 3, Figura 1). Uma hipótese para esse resultado é que, apesar de a forma irregular das partículas da AR1 ter favorecido um melhor arranjo dessa areia, a presença da pasta de cimento aderida à superfície (mais porosa e mais leve) fez com que sua massa unitária fosse menor que a da AN. Já a AR2, além de apresentar fator de empacotamento inferior ao da AN, se mostra mais porosa e mais leve, pois apresenta menor massa unitária que a areia de referência na condição areia composta (Tabela 3, Figura 1).Correlacionando as areias recicladas, observa-se que a AR1 apresenta maiores valores de massa unitária nas "frações finas" ( $\left.\mathrm{AR} 1_{\text {frações finas }}\right)$ e na condição areia composta do que a AR2 (Figura 1). A AR1 também apresenta maior fator de empacotamento dos grãos do que a AR2 (Tabela 3). O maior empacotamento dos grãos leva ao aumento da massa unitária, que, por sua vez, leva a uma estrutura porosa mais "fechada", refletindo de forma positiva no comportamento mecânico dos materiais cimentícios confeccionados com essas frações específicas (LEITE, 2001; METHA; MONTEIRO, 2014). Sendo assim, em relação às características apresentadas acima, a AR1 se mostra mais densa e com granulometria mais contínua que a AR2.

Comparando os valores de absorção de água das areias recicladas (AR1 e AR2), observa-se que a AR1 absorve $79 \%$ a mais de água que a AR2 na fração grossa, reduzindo para $25 \%$ na fração média-grossa. Nas "frações finas" o comportamento se inverte: na fração média-fina os valores de absorção de água são estatisticamente semelhantes, e na fração fina a AR2 chega a absorver 56\% a mais de água do que a AR1. $\mathrm{Na}$ condição areia composta, as areias recicladas não apresentam diferenças estatisticamente significativas (Figura 2a). Com base nos valores de absorção de água, uma hipótese é que as "frações grossas" da AR1 $\left(\mathrm{AR} 1_{\text {frações grossas }}\right)$ apresentam maior presença de pasta de cimento que as "frações grossas" da AR2 (AR $2_{\text {frações }}$ grossas), e o contrário acontece em relação às "frações finas".

Através das comparações colocadas acima, é possível afirmar que as frações das areias recicladas podem ser separadas em dois grupos, com comportamentos e características com tendências distintas: o grupo das "frações grossas" e o grupo das "frações finas". Logo, o estudo mostra que é possível a substituição de um grupo específico de agregados miúdos reciclados, e não apenas sua substituição integral, como tem sido feito. Acredita-se ser possível a aplicação desses novos designs em misturas cimentícias, desde que os agregados reciclados sejam separados em grupos de frações, e estas sejam submetidas aos requisitos propostos pela NBR 15116 (ABNT, 2004b).

\section{Análises químicas}

A soma dos teores de sílica, alumina e óxido de ferro está associada aos silicatos presentes nas rochas, areias e cerâmicas, ao passo que a presença de $\mathrm{CaO}$ e $\mathrm{MgO}$ se refere à pasta de cimento e às rochas de origem calcária. A Figura 3, apresentada a seguir, mostra os teores em porcentagem desses óxidos nas frações granulométricas das areias AN, AR1 e AR2.

$\mathrm{Na}$ Figura 3a, observa-se que as frações da AR1 apresentam teores de sílica, alumina e óxido de ferro superiores aos da AR2, com tendência de crescimento das "frações grossas" para as "frações finas". Em relação aos teores de óxido de cálcio e óxido de magnésio (Figura 3b), observa-se decréscimos para todas as frações granulométricas das areias recicladas, sendo os decréscimos na AR1 mais acentuados que na AR2.

Com base nos ensaios de caracterização físico-química apresentados acima, é possível entender alguns comportamentos e fazer algumas constatações:

(a) na AR1 os grãos do grupo das "frações finas" ( $\left.\mathrm{AR} 1_{\text {frações finas }}\right)$ apresentam teores de sílica, alumina e óxido de ferro maiores do que os encontrados nas "frações grossas" ( $\mathrm{AR} 1_{\text {frações grossas }}$ ), refletindo, assim, na diminuição dos valores de absorção de água;

(b) as análises químicas (Figura 3a) mostram que a fração média-fina da AR1 apresenta 11\% a menos de sílica, alumina e óxido de ferro em relação à areia de referência (AN), sendo que essa diferença chega apenas a $2 \%$ na fração fina. O maior percentual apresentado desses elementos na areia reciclada AR1 pode significar indiretamente menor quantidade de pasta de cimento presente nos grãos;

(c) na AR2 observa-se nas "frações finas" a diminuição dos valores de massa específica e o aumento da absorção de água se comparado aos valores obtidos nas "frações grossas". Ainda que a AR2 apresente teores 
de sílica, alumina e óxido de ferro discretamente maiores nas "frações finas", observa-se a presença considerável de óxido de cálcio e de magnésio em todas as suas frações granulométricas. Parte desses óxidos se refere aos compostos hidratados e não hidratados da pasta de cimento endurecida, constatando-se que mesmo as "frações finas" da AR2 apresentam maior quantidade de pasta aderida em relação ao outro agregado reciclado avaliado; $\mathrm{e}$

(d) os teores de $\mathrm{CaO}$ e $\mathrm{MgO}$ encontrados na $\mathrm{AR} 2$ podem ser justificados em função da origem dos RC que geraram essa areia, corpos de prova de concreto, parte deles produzida com agregados de origem calcária. Já os altos teores de sílica da AR1 também podem ser entendidos em função do material de origem. A AR1 foi beneficiada a partir de RCD compostos de concreto (com agregados de diferentes origens), e, mesmo que o resíduo tenha passado por uma triagem onde a priori apenas resíduos de cor cinza seguiriam para o processo de beneficiamento, outros materiais, como tijolos, telhas e revestimentos cerâmicos, poderiam estar presentes.

Sendo assim, os resultados das análises químicas, além de corroborar os resultados de caracterização física, evidenciam que as frações granulométricas das areias recicladas têm composições distintas (CABRAL, 2007; ULSEN et al., 2014).

O estudo sistêmico das frações granulométricas das areias AR1 e AR2 mostra que a presença e a quantidade de pasta de cimento variaram em função da fração granulométrica analisada e de maneira diferente, a depender de sua origem. A areia de RCD (AR1) apresenta diminuição acentuada do teor de pasta aderida nas "frações finas", enquanto essa redução é mais discreta nas frações da areia de RC (AR2).

\section{Parte 2: Resultados da avaliação das argamassas areias recicladas nos estados fresco e endurecido}

\section{Estado fresco}

Ajustes prévios para a determinação do teor necessário de aditivo foram realizados a fim de alcançar a trabalhabilidade obtida na argamassa de referência. Os teores de aditivo superplastificante utilizados para manter a consistência desejada variaram de $0,02 \%$ a $0,1 \%$ da massa de cimento, ou seja, abaixo da faixa recomendada pelo fabricante, que é de $0,3 \%$ a $1,2 \%$ (Tabela 5). Os baixos teores, em comparação ao sugerido pelo fabricante, foram atribuídos à substituição do agregado natural pelo reciclado em volume, mantendo as mesmas proporções volumétricas das faixas granulométricas utilizadas e a quantidade de água adicionada às misturas, devido à compensação do volume de água absorvido pelos agregados reciclados utilizados nas misturas.

Figura 3 - Gráficos das frações granulométricas das areias: teores em porcentagem de $\mathrm{SiO}_{2}+\mathrm{Al}_{2} \mathrm{O}_{3}+\mathrm{Fe}_{2} \mathrm{O}_{3}$ e de $\mathrm{CaO}+\mathrm{MgO}$

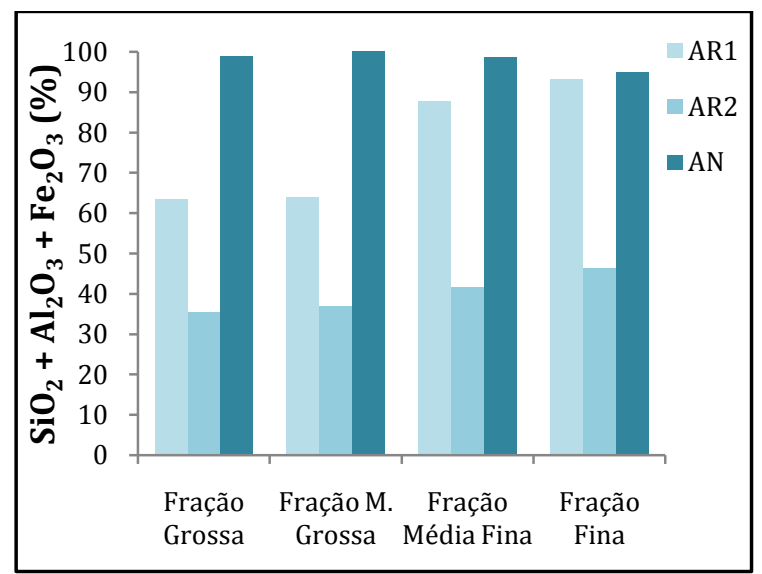

(a)

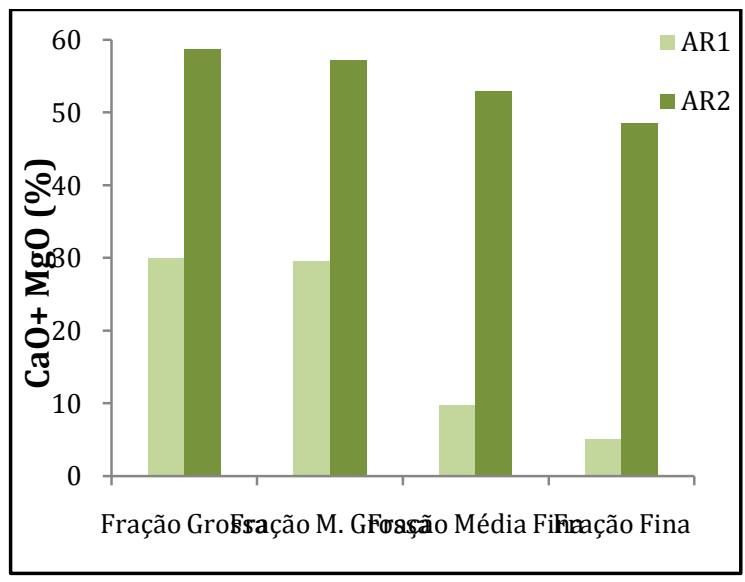

(b)

312 Correa, C. R.; Pereira, C. H.; Rêgo, J. H. S. 
Tabela 5 - Consistências das misturas e as taxas de aditivo superplastificante utilizado na produção das argamassas

\begin{tabular}{l|c|c}
\hline \multicolumn{1}{c|}{ Misturas } & Consistência da mistura (mm) & Taxa de aditivo (\%) \\
\hline $\mathrm{ARG}_{\mathrm{AN}}$ & 131 & - \\
$\mathrm{ARG}_{\mathrm{AR} 1 \mathrm{G}}$ & 122,5 & 0,02 \\
$\mathrm{ARG}_{\mathrm{AR} 2 \mathrm{G}}$ & 125 & 0,02 \\
$\mathrm{ARG}_{\mathrm{AR} 1 \mathrm{MG}}$ & 127,5 & 0,02 \\
$\mathrm{ARG}_{\mathrm{AR} 2 \mathrm{MG}}$ & 120 & 0,02 \\
$\mathrm{ARG}_{\mathrm{AR} 2 \mathrm{MF}}$ & 120 & 0,02 \\
$\mathrm{ARG}_{\mathrm{AR} 1 \mathrm{~F}}$ & 122 & 0,02 \\
$\mathrm{ARG}_{\mathrm{AR} 2 \mathrm{~F}}$ & 115,5 & 0,03 \\
$\mathrm{ARG}_{\mathrm{AR} 1100 \%}$ & 115 & 0,03 \\
$\mathrm{ARG}_{\mathrm{AR} 2100 \%}$ & 115 & 0,10 \\
\hline
\end{tabular}

Ressalta-se que não foi avaliada a incorporação de ar nas argamassas ocasionada pela utilização do aditivo superplastificante devido ao baixo teor utilizado nas misturas e pela manutenção do procedimento de mistura para todas as argamassas do estudo.

Observa-se que, apesar de não significativo e mantendo-se dentro do intervalo estabelecido de $125 \pm 10 \mathrm{~mm}$, foi necessário aumentar o teor de aditivo com a substituição de $100 \%$ do agregado natural pela AR2, obtendo-se o valor-limite inferior de espalhamento determinado para o ensaio de avaliação da consistência das argamassas.

\section{Estado endurecido}

Os resultados de resistência à compressão da argamassa de referência e das argamassas recicladas aos 28 dias são apresentados na Figura 4. A linha tracejada no gráfico se refere ao valor de resistência à compressão da argamassa de referência $\left(\mathrm{ARG}_{\mathrm{AN}}\right)$.

Os resultados dos ensaios de caracterização física mostraram que as areias recicladas absorvem mais água e apresentam menores valores de massa unitária que a areia de referência (Figuras 1 e 2a).Logo, justifica-se o maior valor de resistência à compressão dessa argamassa em relação às argamassas recicladas: $\mathrm{ARG}_{\mathrm{AR} 1 \mathrm{G}}$, $\mathrm{ARG}_{\mathrm{AR} 1 \mathrm{MG}}, \mathrm{ARG}_{\mathrm{AR} 2 \mathrm{MG}}, \mathrm{ARG}_{\mathrm{AR} 1100 \%}$ e $\mathrm{ARG}_{\mathrm{AR} 2100 \%}$ (Figura 4). Os menores valores de resistência à compressão obtidos para essas argamassas são atribuídos à presença da camada de pasta de cimento aderida à superfície dos grãos das "frações grossas" da AR1 e da fração média-grossa da AR2.

A resistência à compressão da argamassa $A R G_{A R 2 G}$ não apresentoudiferença estatística significativa em relação à da argamassa de referência. Atribui-se esse resultado ao baixo patamar dos valores de absorção de água da fração grossa da AR2 (1,1\%) (Figura 2a).

Comparando os resultados de resistência à compressão das $\mathrm{ARG}_{\mathrm{AR} 1 \mathrm{G}}$ e $\mathrm{ARG}_{\mathrm{AR} 2 \mathrm{G}}$, observa-se que o valor de absorção de água da fração grossa da AR1 é $79 \%$ maior que a da AR2 (Figura 2a). Os resultados de caracterização física das areias corroboram os resultados de resistência à compressão das argamassas. A argamassa $\mathrm{ARG}_{\mathrm{AR} 2 \mathrm{G}}$ apresenta valore de resistência à compressão 21,6\% maior que a argamassa $\mathrm{ARG}_{\mathrm{AR} 1 \mathrm{G}}$ (Figura 4).

Estatisticamente não há diferença significativa entre os valores de resistência à compressão das argamassas $\mathrm{ARG}_{\mathrm{AR} 1 \mathrm{MG}}$ e $\mathrm{ARG}_{\mathrm{AR} 2 \mathrm{MG}}$ (Figura 4).

Comparando as argamassas com $100 \%$ de areia reciclada com a argamassa de referência, observa-se que a $\mathrm{ARG}_{\mathrm{AN}}$ apresenta valor de resistência à compressão $21,4 \%$ maior que a argamassa $\mathrm{ARG}_{\mathrm{AR} 1100 \%}$ e $52 \%$ maior que a argamassa $\mathrm{ARG}_{\mathrm{AR} 2100 \%}$. Tais valores corroboram os resultados de caracterização física das areias recicladas na condição areia composta, que mostraram que estas absorviam mais água e apresentavam menores valores de massa unitária do que a AN (Figuras 1 e 2a).

Comparando as argamassas $\mathrm{ARG}_{\mathrm{AR} 1100 \%} \mathrm{e} \mathrm{ARG}_{\mathrm{AR} 2100 \%}$, nota-se que a primeira apresenta resistência à compressão 39\% maior que a última (Figura 4). Os ensaios físicos realizados nas areias justificam tais resultados. A AR2 na condição areia composta apresentou valores de massa unitária e fator de empacotamento dos grãos menores que os da AR1, 8\% e 11,3\% respectivamente (Figura 1, Tabela 3). 
Figuras 4 - Resistência à compressão das argamassas de referência (AN) e recicladas aos 28 dias de idade, em $\mathrm{MPa}$

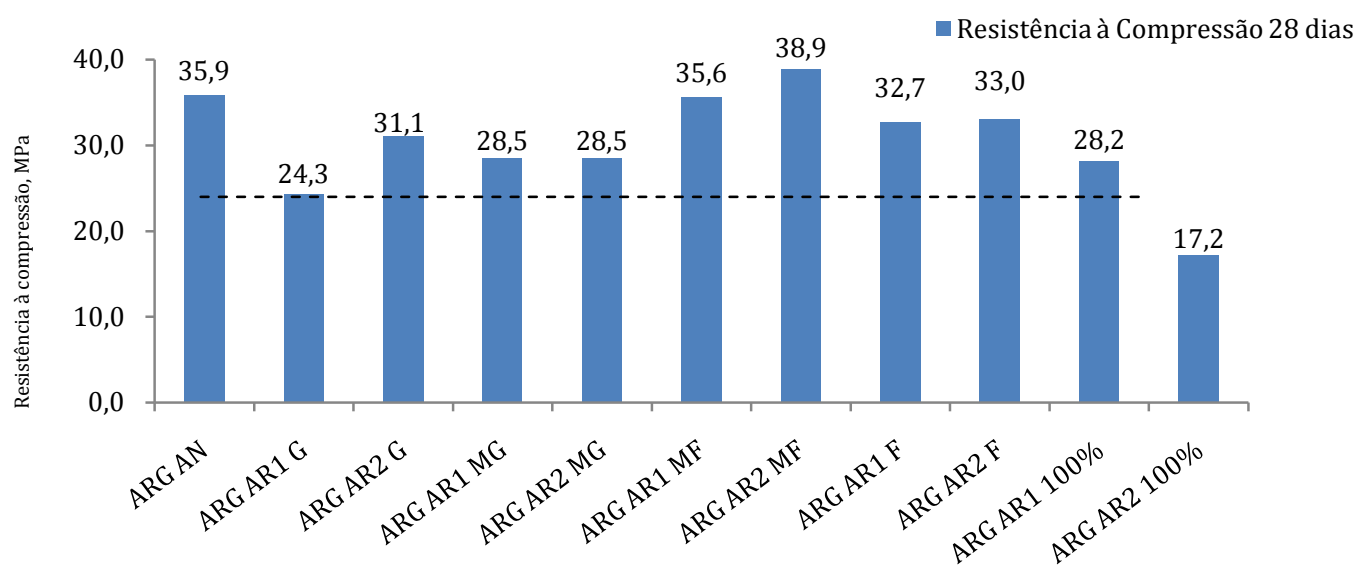

Tabela 6 - Valores de resistência das argamassas à tração por compressão diametral aos 28 dias de idade, em MPa

\begin{tabular}{cccccc}
\cline { 3 - 6 } & $\mathrm{ARG}_{\mathrm{AR} 1 \mathrm{G}}$ & $\mathrm{ARG}_{\mathrm{AR} 1 \mathrm{MG}}$ & $\mathrm{ARG}_{\mathrm{AR} 1 \mathrm{MF}}$ & $\mathrm{ARG}_{\mathrm{AR} 1 \mathrm{~F}}$ & $\mathrm{ARG}_{\mathrm{AR} 1100 \%}$ \\
\cline { 1 - 4 } $\mathrm{ARG}_{\mathrm{AN}}$ & 4,02 & 4,48 & 3,93 & 3,89 & 3,59 \\
\cline { 3 - 7 } 3,59 & $\mathrm{ARG}_{\mathrm{AR} 2 \mathrm{G}}$ & $\mathrm{ARG}_{\mathrm{AR} 2 \mathrm{MG}}$ & $\mathrm{ARG}_{\mathrm{AR} 2 \mathrm{MF}}$ & $\mathrm{ARG}_{\mathrm{AR} 2 \mathrm{~F}}$ & $\mathrm{ARG}_{\mathrm{AR} 2100 \%}$ \\
\cline { 5 - 8 } & 4,70 & 4,59 & 3,34 & 3,23 & 3,69 \\
\hline
\end{tabular}

Quanto às argamassas $\mathrm{ARG}_{\mathrm{AN}}, \mathrm{ARG}_{\mathrm{AR} 1 \mathrm{MF}}, \mathrm{ARG}_{\mathrm{AR} 1 \mathrm{~F}}, \mathrm{ARG}_{\mathrm{AR} 2 \mathrm{MF}}$ e $\mathrm{ARG}_{\mathrm{AR} 2 \mathrm{~F}}$, os resultados dos ensaios de resistência à compressão mostram que todas são estatisticamente semelhantes (Figura 4). As massas específicas das frações média-fina, fina e areia composta se apresentaram estatisticamente semelhantes (Figura 2b), e as areias apresentaram diferenças estatísticas significantes em relação à absorção de água. Contudo, tais diferenças não chegaram a impactar nos valores de resistência à compressão dessas argamassas.

Acredita-se que os resultados das argamassas $A R G_{A R 1 M F}$ e $A_{R G_{A R 1 F}}$ sejam explicados com a diminuição da presença de pasta de cimento nas $\mathrm{AR} 1_{\text {frações finas }}$, comprovada indiretamente através da elevação dos teores de sílica, alumina e óxido de ferro nessas frações (Figura 3a).

Em relação às argamassas recicladas $\mathrm{ARG}_{\mathrm{AR} 2 \mathrm{MF}}$ e $\mathrm{ARG}_{\mathrm{AR} 2 \mathrm{~F}}$, as análises químicas mostraram discreto aumento dos teores de sílica, alumina e óxido de ferro nas AR $2_{\text {frações finas (Figura 3a). Observou-se também }}$ nessas frações a presença de cerca de $50 \%$ de óxido de cálcio e de magnésio (Figura 3b). Logo, uma hipótese para seus resultados seria a de que os níveis mais elevados de cimento (hidratado ou nãohidratado), associados principalmente à presença do $\mathrm{CaO}$, poderiam ter aumentado a quantidade total de cimento na mistura, elevando os valores de resistência à compressão das argamassas $\mathrm{ARG}_{\mathrm{AR} 2 \mathrm{MF}}$ e $\mathrm{ARG}_{\mathrm{AR} 2 \mathrm{~F}}$ (ULSEN et al., 2013; LI et al., 2015; BALDUSCO et al., 2017).

Os resultados apresentados acima mostraram que as substituições de $25 \%$ foram efetivas em avaliar a influência das características das frações granulométricas das areias recicladas na resistência à compressão das argamassas.

A Tabela 6, a seguir, se refere à resistência à tração das argamassas de referência e das recicladas.

A avaliação estatística aponta que a argamassa de referência e as argamassas recicladas apresentam resistência à tração similares. Como os agregados reciclados costumam apresentar características como textura rugosa e forma angular, que melhoram a aderência e favorecem a resistência à tração, essas características podem justificar os resultados de resistência à tração alcançados pelas argamassas recicladas avaliadas (BUTTER, 2003; RATO, 2006).

314 Correa, C. R.; Pereira, C. H.; Rêgo, J. H. S. 


\section{Conclusão}

As análises estatísticas indicaram que as areias recicladas são compostas de dois grupos, o grupo das "frações grossas" e o grupo das "frações finas", com comportamentos e características distintos. O teor de substituição de $25 \%$ foi efetivo para avaliar a influência das frações granulométricas das areias recicladas no comportamento físico-mecânico de argamassas.

Concluiu-se ainda que:

(a) a presença de pasta de cimento varia dependendo da fração granulométrica e da origem da areia reciclada;

(b) as $\mathrm{AR} 1_{\text {frações finas }}$ apresentam menor presença de pasta de cimento em relação às $\mathrm{AR} 1_{\text {frações grossas, }}$, assemelhando-se às frações da areia de referência (AN). Ao contrário, as $A R 2_{\text {frações grossas }}$ apresentam menor presença de pasta de cimento em relação às $\mathrm{AR} 2_{\text {frações finas; }}$

(c) para o teor de substituição de $25 \%$, os resultados de resistência à compressão mostram que a fração fina e a fração média-fina não causam alterações físico-mecânicos às argamassas, pois se comportam de forma similar à argamassa de referência;

(d) a argamassa $\mathrm{ARG}_{\mathrm{AR} 2 \mathrm{G}}$ apresenta resistência à compressão superior à argamassaARG $\mathrm{AR}_{\mathrm{AR} G}$;

(e) para substituições de $100 \%$, a argamassa $\mathrm{ARG}_{\mathrm{AR} 1100 \%}$ apresenta resistência à compressão superior à da argamassa $\mathrm{ARG}_{\mathrm{AR} 2100 \%}$, o que corrobora os resultados dos ensaios físicos que mostraram que na condição areia composta a AR1 se mostra mais densa e com granulometria mais contínua do que a AR2; e

(f) as argamassas recicladas com $25 \%$ ou $100 \%$ de substituição obtiveram resultados de resistência à tração semelhantes à argamassa de referência. Tais resultados foram influenciados pela forma e pela textura dos grãos das areias recicladas AR1 e AR2.

\section{Referências}

ANGULO, S. C. Caracterização deagregados de resíduos de construção e demolição reciclados e a influência de suas características no comportamento de concretos. São Paulo, 2005. Tese (Doutorado em Engenharia Civil) - Escola Politécnica, Universidade de São Paulo, São Paulo, 2005.

ASSOCIAÇÃO BRASILEIRA DE NORMAS TÉCNICAS. NBR 15116: agregados reciclados de resíduos sólidos da construção civil: utilização em pavimentação e preparo de concreto sem função estrutural: requisitos. Rio de Janeiro, 2004b.

ASSOCIAÇÃO BRASILEIRA DE NORMAS TÉCNICAS. NBR 7214: areia normal para ensaio de cimento. Rio de Janeiro, 2015.

ASSOCIAÇÃO BRASILEIRA DE NORMAS TÉCNICAS. NBR 7215: cimento Portland: determinação da resistência à compressão. Rio de Janeiro, 2019.

ASSOCIAÇÃO BRASILEIRA DE NORMAS TÉCNICAS. NBR 7222: concreto e argamassa: determinação da resistência à tração por compressão diametral de corpos de prova cilíndricos. Rio de Janeiro, 2011.

ASSOCIAÇÃO BRASILEIRA DE NORMAS TÉCNICAS. NBR NM 30: agregado miúdo determinação da absorção de água. Rio de Janeiro, 2001.

ASSOCIAÇÃO BRASILEIRA DE NORMAS TÉCNICAS. NBR NM 45: agregados: determinação da massa unitária e do volume de vazios. Rio de Janeiro, 2004a.

ASSOCIAÇÃO BRASILEIRA DE NORMAS TÉCNICAS. NBR NM 52: agregado miúdo: determinação de massa específica e massa específica aparente. Rio de Janeiro, 2003.

ASSOCIAÇÃO BRASILEIRA PARA RECICLAGEM DE RESÍDUOS DA CONSTRUÇÃO CIVIL E DEMOLIÇÃO. Relatório Pesquisa Setorial 2014/2015. São Paulo, 2015.

BALDUSCO DA SILVA, R. et al. Dry cost concretes produced with density-separated-crushed-CDW recycled aggregates. Ambiente Construído, Porto Alegre, v. 15, n. 4, p. 335-349, out./dez. 2015.

BALDUSCO, R. et al. Reatividade e resistência mecânica de pastas reidratadas de cimento de alto forno.In: ENCONTRO NACIONAL SOBRE APROVEITAMENTO DE RESÍDUOS NA CONSTRUÇÃO, 5. Fortaleza, 2017. Anais [...] Fortaleza, 2017. 
BEDOYA, C.; DZUL, L. Concrete with recycled aggregates as urban sustainability project. Revista Ingenieria de Construccion, v. 30, n. 2, p. 99-108, 2015.

BUTTLER, A M. Concreto com agregados graúdos reciclados de concreto: influência da idade de reciclagem nas propriedades dos agregados e concretos reciclados. São Carlos, 2003. 220 f. Dissertação (Mestrado em Engenharia de Estruturas) - Escola de Engenharia de São Carlos, Universidade de São Paulo, São Carlos, 2003.

CABRAL, A. E. B. Modelagem de propriedades mecânicas e de durabilidade de concretos produzidos com agregados reciclados, considerando-se a variabilidade da composição do RCD. São Carlos, 2007. Tese (Doutorado em Ciências da Engenharia Ambiental) - Escola de Engenharia de São Carlos, Universidade de São Paulo, São Carlos, 2007.

EVANGELISTA, L. et al. Physical, chemical and mineralogical properties of fine recycled aggregates made from concrete waste. Construction and Building Materials, v. 86, p. 178-188, 2015.

EVANGELISTA, L.; DE BRITO, J. Durability performance of concrete made with fine recycled concrete aggregates. Cement and Concrete Composites, v. 32, n. 1, p. 9-14, 2010.

GIRARDI, A. C. C; MARTINS FILHO, P. C.; CARASEK, H. Análise comparativa de parâmetros de argamassas produzidas com agregado reciclado de RCD misto e cimentício. In: ENCONTRO NACIONAL SOBRE APROVEITAMENTO DE RESÍDUOS NA CONSTRUÇÃO, 5., Fortaleza, 2017. Anais [...] Fortaleza, 2017.

KAHN, H. et al. Automated image analys is on the quantification of recycled aggregates phases 2 materiais e métodos. Holos, v. 3, p. 44-52, 2014.

LEITE, M. B. Avaliação de propriedades mecânicas de concretos produzidos com agregados reciclados de resíduos de construção e demolição. Porto Alegre, 2001. Tese (Doutorado em Engenharia Civil) Programa de Pós-Graduação em Engenharia Civil, Universidade Federal do Rio Grande do Sul, Porto Alegre, 2001

LI, G. et al. Properties of cement-based bricks with oyster-shells ash. Journal of Cleaner Production, v. 91, n. 15, p. 279-287, mar. 2015.

MALTA, J. O. et al. Influência da pré-saturação do agregado miúdo reciclado na viscosidade e resistência à compressão das argamassas. Ambiente Construído, Porto Alegre, v. 14, n. 1, p. 85-98, jan./mar. 2014.

MARTÍNEZ, I. et al. A comparative analysis of the properties of recycled and natural aggregate in masonry mortars. Construction and Building Materials, v. 49, p. 384-392, 2013.

MEHTA, P. K.; MONTEIRO, P. J. M. Concreto: microestrutura, propriedades e materiais. 2. ed. Natal: Ibracon, 2014.

MIRANDA, R. J. N. Betão com agregados reciclados: estado da arte e análise à gestão eutilização na região autónoma da madeira. Funchal, 2014. Dissertação (Mestrado em Engenharia Civil) - Centro de Competência de Ciências Exatas e da Engenharia, Universidade da Madeira, Funchal, 2014.

PACHECO-TORGAL, F. Handbook of recycled concrete and demolotion waste. $2^{\text {nd. }}$ ed. Oxford: [s.n.], 2013.

RATO, V. N. D. P. M. Influência da microestrutura morfológica no comportamento de argamassas. Lisboa, 2006. Tese (Doutorado em Engenharia Civil) - Faculdade de Ciências e Tecnologia, Universidade Nova de Lisboa, Lisboa, 2006.

RODRIGUES, C. R. S.; FUCALE, S. Dosagem de concretos produzidos com agregado miúdo reciclado de resíduos da construção civil. Ambiente Construído, Porto Alegre, v. 14, n. 1, p. 99-111, jan./mar. 2014.

SILVA, R. V.; DE BRITO, J.; DHIR R. K. Properties and Composition of Recycled Aggregates from Construction and Demolition Waste Suitable for Concrete Production. Construction and Building Materials, v. 63, p. 201-217, 2014.

TAYLOR, H. F. W. Cement Chemistry. $3^{\text {th. }}$ ed. London: Thomas Telford, 1997.

ULSEN, C. Caracterização e separabilidade de agregados miúdos produzidos a partir de resíduos de construção e demolição. São Paulo, 2011. Tese (Doutorado em Engenharia Mineral) - Escola Politécnica, Universidade de São Paulo, São Paulo, 2011. 
ULSEN, C. et al. Composição química de agregados mistos de resíduos de construção e demolição do estado de São Paulo. Mineração, v. 63, n. 2, p. 339-346, 2010.

ULSEN, C. et al. Production of recycled sand from construction and demolition waste. Construction and Building Materials, v. 40, p. 1168-1173, 2013.

ULSEN, C. et al. Separabilidade de agregados reciclados provenientes de resíduos de construção e demolição de diferentes origens. Holos, v. 1, p. 8, 2014.

\section{Agradecimentos}

À UnB, em especial aos professores Cláudio Henrique de Almeida Feitosa Pereira e João Henrique da Silva Rêgo, ao Instituto Federal de Brasília (IFB) e à Fundação de Apoio à Pesquisa do Distrito Federal (FAPDF). Processo 0193002038/2017-17. À Capes e ao CNPq.

\section{Cássia Rabelo Correa}

Instituto Federal de Brasília | Campus Samambaia, Subcentro Leste, Samambaia Sul | Brasíia - DF - Brasil | Tel.: (61) 2103-2300 | E-mail: cassia.rabelo@ifb.edu.br

\section{Cláudio Henrique Pereira}

Programa de Pós-Graduação em Estruturas e Construção Civil | Universidade de Brasília | Campus Darcy Pacheco, Prédio $12,1^{\circ}$ andar | Brasília - DF - Brasil | CEP 70910-900 | Tel.: (61) 3107-0990 | E-mail: claudiopereira@unb.br

João Henrique Silva Rêgo

Programa de Pós-Graduação em Estruturas e Construção Civil | Universidade de Brasília | E-mail: jhenriquerego@unb.br

\section{Ambiente Construído}

Revista da Associação Nacional de Tecnologia do Ambiente Construído

Av. Osvaldo Aranha, $99-3^{\circ}$ andar, Centro

Porto Alegre - RS - Brasil

CEP $90035-190$

Telefone: +55 (51) 3308-4084

Fax: +55 (51) 3308-4054

www.seer.ufrgs.br/ambienteconstruido

E-mail: ambienteconstruido@ufrgs.br 